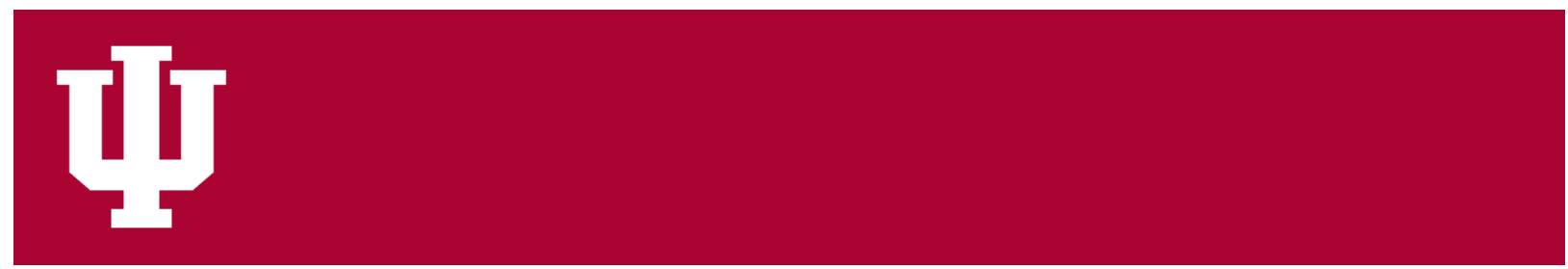

IUScholarWorks at Indiana University South Bend

\title{
Novel Plant Secondary Metabolites \\ Impact Dietary Specialists More Than Generalists (Neotoma Spp.)
}

Sorensen, Jennifer S.; McLister, James D.; Dearing, M. Denise

To cite this article: Sorensen, Jennifer, et al. "Novel Plant Secondary Metabolites Impact Dietary Specialists More Than Generalists (Neotoma Spp.).” Ecology, vol. 86, no. 1, 2005, pp. 140-54, doi:10.1890/03-0669.

This document has been made available through IUScholarWorks repository, a service of the Indiana University Libraries. Copyrights on documents in IUScholarWorks are held by their respective rights holder(s). Contact iusw@indiana.edu for more information. 


\title{
NOVEL PLANT SECONDARY METABOLITES IMPACT DIETARY SPECIALISTS MORE THAN GENERALISTS (NEOTOMA SPP.)
}

\author{
Jennifer S. Sorensen, ${ }^{1}$ James D. McLister, ${ }^{2}$ and M. Denise Dearing \\ Biology Department, University of Utah, Salt Lake City, Utah 84112 USA
}

\begin{abstract}
Theory predicts that dietary specialization is limited in part because of physiological trade-offs associated with specialization. Specifically, dietary specialists are predicted to evolve mechanisms that reduce costs and enhance excretion of plant secondary metabolites (PSMs) that they frequently consume, but are less energetically and/or mechanistically efficient at eliminating novel PSMs. Although examples of trade-offs associated with dietary specialization have been documented among insects, trade-offs have not been investigated in mammalian herbivores. To initially investigate the physiological trade-offs associated with specialization in mammalian herbivores, we determined the impact of ingesting novel PSMs on the energy budgets of a juniper specialist (Neotoma stephensi) and generalist $(N$. albigula) woodrat. These results were then compared to the impact of juniper intake, the plant species preferred by the specialist, on energy budgets in these same species. Energy budgets were evaluated by measuring apparent metabolizable energy intake (AMEI, energy consumed - energy excreted) and energy expended on basal metabolic rate (BMR) and voluntary wheel running in specialist and generalist woodrats fed a formulated diet with and without PSMs from the novel plant creosote (Larrea tridentata). Both specialists and generalists were energetically impacted by the intake of a diet containing novel PSMs, primarily through decreased intake of creosote diet and increased excretion of energy in the urine. However, specialists were impacted to a greater extent than generalists. Specialists decreased body mass, whereas generalists maintained body mass. Specialists also reduced intake and AMEI when consuming creosote diet compared to control to a greater extent than generalists. In turn, specialists had one-sixth the energy available for energy dependent activities than generalists on a diet containing novel PSMs. These results are in stark contrast to the comparisons between specialists and generalists consuming PSMs from their natural diet. Specialists consumed more juniper, had higher AMEI and available energy than generalists when fed diets containing juniper foliage. These data provide the first support that physiological trade-offs associated with dietary specialization may exist in mammalian herbivores.
\end{abstract}

Key words: generalist; mammalian herbivore; Neotoma albigula; Neotoma stephensi; novel PSM; specialist; trade-off.

\section{INTRODUCTION}

A central goal in the study of plant-mammal interactions has been to identify factors that limit dietary specialization. Previous studies have focused on identifying the energetic costs and physiological constraints associated with ingesting and detoxifying the limited spectrum of secondary metabolites present in a single plant species (Foley and McArthur 1994, Boyle et al. 1999a, Dearing et al. 2000, Sorensen and Dearing 2003, Sorensen et al. 2004). These studies suggest that the high costs and limited capacity to eliminate secondary metabolites from a single species of plant limit the occurrence of dietary specialists. Integrated within

Manuscript received 6 October 2003; revised 29 April 2004; accepted 12 May 2004; final version received 3 June 2004. Corresponding Editor: B. J. Danielson.

${ }^{1}$ Present address: Oregon State University-Cascades Campus, 234 Cascades Hall, 2600 NW College Way, Bend, OR 97701 USA. E-mail: jennifer.sorensen@oregonstate.edu

${ }^{2}$ Present address: Department of Biological Science, Indiana University, South Bend, Indiana 46634-7111 USA. the limitations of dietary specialization is the prediction that specialists have a reduced capacity to consume novel foods. Specifically, dietary specialists are predicted to have evolved mechanisms to reduce costs and enhance excretion of plant secondary metabolites (PSMs) that they frequently consume. However, this physiological specialization may result in a decreased capacity to eliminate novel PSMs. A lower capacity to process a wide range of PSMs may restrict specialization to habitats where their preferred plant species is abundant and/or make specialists less resistant to changes in plant availability. Although examples of trade-offs associated with dietary specialization have been documented among insects (Futuyma and Moreno 1988, Berenbaum and Zangerl 1994, Mackenzie 1996), trade-offs have not been investigated in mammalian herbivores.

The few specialist mammalian herbivores that exist demonstrate marked physiological advantages over their generalist counterparts when both are consuming the preferred plant of the specialist. Specialists con- 
sume greater quantities, lose less body mass, experience fewer signs of toxicity, and maintain more positive energy balance on their preferred plant compared to generalists (Atsatt and Ingram 1983, Lawler et al. 1998, Dearing et al. 2000, Marsh et al. 2003, Sorensen et al. 2005). Specialists also use less expensive detoxification mechanisms (Boyle et al. 1999a) and eliminate PSMs from the body more efficiently than generalists (Sorensen and Dearing 2003, Sorensen et al. 2004). These data indicate that specialists have a significant advantage over generalists when consuming their preferred plant species.

The impact of ingesting novel PSMs has received little attention in plant-mammal interactions (Atsatt and Ingram 1983, Mangione et al. 2000). Furthermore, no studies have directly investigated how mammalian specialists perform on diets containing novel plants and compared their performance to that of a generalist fed the same novel plant. We examined the foraging constraints of dietary specialization by investigating the performance of juniper specialist (Neotoma stephensi) and generalist ( $N$. albigula) woodrats consuming PSMs that were novel to both woodrat species. In addition, we compared the performance of these two woodrat species on a novel plant species to their performance on a naturally consumed plant species.

These species of woodrats provide an exceptional opportunity to initially investigate the physiological trade-offs associated with dietary specialization. Neotoma stephensi and $N$. albigula are closely related woodrats that occur sympatrically in Great Basin ecotones. In addition, Juniperus monosperma, the plant species on which $N$. stephensi specializes, is included within the diet of $N$. albigula. Although it is has not been demonstrated that $N$. stephensi "prefers" juniper over other plant species, we designate juniper as the "preferred" plant species of $N$. stephensi due to the fact that $N$. stephensi feed almost exclusively on juniper (80-95\% Juniperus monosperma) and are only found in juniper habitat (Vaughan and Czaplewski 1985). $N$. albigula also consume juniper (17-33\%) along with yucca (29\%) and other plant species in lower quantities (Dial 1988). Previous studies demonstrated that N. stephensi performed better and was less energetically impacted than $N$. albigula when both were fed diets containing high concentrations of juniper (Sorensen et al. 2005). Based on foraging differences and performance on juniper, $N$. stephensi will be referred to as a "specialist" and N. albigula will be referred to as a "generalist" for simplicity.

We carried out a series of experiments to examine the impact of ingesting novel PSMs on the performance of specialist and generalist woodrats. We used phenolic resin from creosote bush (Larrea tridentata) as the novel PSM. Creosote bush contains large quantities of PSMs that are toxic to other species of woodrats (Meyer and Karasov 1989, Mangione et al. 2000, 2001). Creosote bush is not presently or historically found in the shared habitat of specialists and generalists (Dial and Czaplewski 1990) and therefore represents a plant with PSMs that are novel to these species of woodrats. Although creosote and juniper both contain phenolic compounds, the classes of phenolics and specific compounds differ between the two plant species (Mabry and Gill 1979, Adams et al. 1981). For example, the most abundant phenolic in creosote, nordihydroguaiaretic acid (NDGA, 4-12\% of dry mass), is not present in juniper. In addition, there is no evidence that NDGA is present in any of the plants consumed by either specialists or generalists. Furthermore, yucca is the only plant not consumed to some extent by both specialists and generalists (Dial 1988) and it does not contain phenolic resins. It is therefore assumed that neither species has had evolutionary or ecological (including developmental) experience with the major PSMs in creosote resin.

We hypothesized (1) that the intake of PSMs from creosote would negatively impact energy acquisition and expenditure in woodrats; (2) that specialists would be more energetically impacted by the intake of PSMs from creosote than generalists; and (3) that, relative to generalists, specialists would perform better on its preferred plant species than a novel plant. In general, performance was examined by measuring energy acquisition and expenditure in specialist and generalist woodrats on control diet and diet containing PSMs from creosote bush. Additionally, the physiological trade-offs hypothesis associated with specialization was tested by comparing the performance of specialists on their preferred plant versus a novel plant and examining these differences relative to the performance of generalists on the same diets.

\section{Methods \\ Woodrats}

Specialist (Neotoma stephensi) and generalist (N. albigula) woodrats were trapped near Wupatki National Park, $45 \mathrm{~km}$ northeast of Flagstaff, Arizona, USA $\left(35^{\circ} 30^{\prime} \mathrm{N}, 111^{\circ} 27^{\prime} \mathrm{W}\right)$ and transported to the University of Utah Animal Facility. Woodrats were housed in individual cages $(48 \times 27 \times 20 \mathrm{~cm})$ with bedding and cotton batting and put on a 12:12-h light:dark cycle for at least 6 months prior to experiments. All experiments took place at $27-28^{\circ} \mathrm{C}$, which is within the thermoneutral zone of these woodrats (McLister et al. 2004). All animals were fed pelleted rabbit chow (formula 2031; Harlan Teklad, Madison, Wisconsin, USA) and water ad libitum prior to experimentation.

Ten specialist (five male, five female) and nine generalist (five male, four female) woodrats were given continuous access to a running wheel (Nalgene Wheel Assembly 640-0700; Mini Mitter Company, Bend, Oregon, USA). Wheels were provided at least $10 \mathrm{~d}$ prior to experimentation to familiarize woodrats to wheels. One day prior to experimentation, woodrats 
were placed in "metabolic cages" that permitted separate collection of urine and feces and provided continuous access to wheels. Metabolic cages were standard shoebox cages fitted with a feeder (Nalgene 6500104) and mesh stainless steel bottoms (Nalgene 6762154) suspended over a stainless steel mesh platform and a Plexiglas ramp that allowed for fecal and urinary collections.

\section{Performance on a diet containing novel PSMs}

The performance of specialist and generalist woodrats was evaluated on a diet containing novel PSMs from creosote bush. Woodrats were given a sequential series of control, acclimation, and creosote diets. Woodrats were maintained on the control diet for $7 \mathrm{~d}$. Woodrats were then fed an acclimation diet containing $1 \%$ creosote resin (by dry mass $[\mathrm{dm}]$ ) for $3 \mathrm{~d}$, which is the time required to induce detoxification enzymes (Sipes and Gandolfi 1986). Immediately following the acclimation diet, woodrats were fed a $2 \%$ creosote resin diet (by $\mathrm{dm}$ ) for $7 \mathrm{~d}$ (see Appendix). A 2\% creosote resin diet was the maximum concentration that specialists and generalists could tolerate without rapid and excessive loss of body mass ( $<3 \%$ daily). Based on the resin concentration in creosote $(4.7 \%$ by dry mass) and the daily intake of woodrats $(\sim 11.5 \mathrm{~g}$ dry mass/ d), a diet containing $2 \%$ resin would represent a diet consisting of $\sim 20 \%$ creosote leaves.

We extracted creosote resin for addition to diets from creosote leaves collected in the field. Creosote leaves were collected randomly from eight to ten Larrea tridentata bushes from the Mojave Desert near Beaver Dam in Grand County, Utah $\left(37^{\circ} 06^{\prime} \mathrm{N}, 113^{\circ} 58^{\prime} \mathrm{W}\right)$ on 8-9 May 2001. A collection of both young and mature leaves were stripped from branches by hand. Leaves were placed immediately on dry ice until arrival at the University of Utah, where they were stored at $-20^{\circ} \mathrm{C}$. Resin was extracted from creosote foliage by submerging creosote leaves in ethyl ether for $45 \mathrm{~min}$ (1:6 wet leaf mass:volume solvent ratio). The extract was filtered (Whatman no. 10 paper) and ethyl ether was evaporated from the resin extract using a rotovap until the resin was a dense, viscous consistency. The remaining ethyl ether was removed from the resin using a vacuum pump for $48 \mathrm{~h}$. The extraction procedure yielded $4.7 \%$ powdered creosote resin by dry mass of creosote leaves. The resin was stored at $-20^{\circ} \mathrm{C}$ for less than 5 mo. Creosote treatment diets were prepared by dissolving the desired amount of resin into ethyl acetate and applying the ethyl acetate-resin mixture to ground rabbit chow using a volume equal to $25 \%$ of the dry mass of chow. The control diet was prepared by applying ethyl acetate to the chow ( $25 \%$ by dry mass). Ethyl acetate was completely evaporated from diet treatments in a fume hood. Complete evaporation was confirmed gravimetrically and dry diet treatments were stored at $-20^{\circ} \mathrm{C}$.
Diet was provided to woodrats daily in excess of intake requirements to maintain body mass. Diets were offered at approximately 16:00 each day for a 24-h period. Water was provided ad libitum throughout the experiment. Body mass was measured every $3 \mathrm{~d}$ on the control diet and every other day on the creosote diet. Any animal losing more than $12 \%$ of body mass during the creosote diet treatment was removed from the experiment. Body mass measured on the last days of control and creosote diet treatments was used for comparisons between specialists and generalists.

\section{Performance}

Performance was evaluated by comparing apparent metabolizable energy intake (AMEI) and expenditure between specialists and generalists on control and creosote diets. AMEI was defined as the energy ingested that was not excreted in feces or urine and was considered apparent rather than true metabolizable energy because there was no correction for endogenous energy lost in urine and feces. We measured two critical components of energy expenditure: basal metabolic rate (BMR) and voluntary wheel running (an index of locomotion). We assumed that energy was not utilized for growth, reproduction or thermoregulation, as all woodrats were nonreproducing adults within their thermoneutral zone. "Surplus energy" was estimated as the amount of AMEI not expended on BMR and voluntary wheel running. Surplus energy is not necessarily considered "extra" energy that can be stored, but is considered the energy that can be used by woodrats for daily activities (i.e., remaining alert, grooming) or lost during specific dynamic action and/or methane production. Surplus energy could also be used by woodrats for activities such as growth, reproduction and thermoregulation.

Apparent metabolizable energy intake.-AMEwas determined for specialists and generalists on control and creosote diets as the energy ingested that was not excreted in feces and urine. AMEI was determined from samples collected and averaged during the last $3 \mathrm{~d}$ of control and creosote diet treatments. Uneaten diet and excreted feces and urine were collected daily and pooled for the last $3 \mathrm{~d}$ of each diet treatment. All diet treatments were $98 \%$ dry and water content did not change during the 24-h feeding period. Dry matter intake was therefore calculated by ([diet given - diet remaining] $\times 0.98$ ), with diet measured in grams. The 3 -d fecal and urine collections were combined separately for feces and urine and stored at $-20^{\circ} \mathrm{C}$. A subsample of each three-day pooled sample was dried completely at $45^{\circ} \mathrm{C}$ to determine daily dry matter output of feces and urine. Energy per gram $(\mathrm{kJ} / \mathrm{g})$ of dry diet treatments, feces, and urine was measured with a microbomb calorimeter (1261 Isoperibol Calorimeter; Parr Instruments, Moline, Illinois, USA). Benzoic acid was used as a standard. Analyses were done in duplicate and repeated if the values differed by $>5 \%$. Energy 
intake was determined as the product between daily intake $(\mathrm{g} / \mathrm{d})$ and energy per gram diet. Daily energy excreted in feces and urine was determined as the product between daily output $(\mathrm{g} / \mathrm{d})$ and energy per gram of feces or urine. Because energy loss in urine and fecal were determined on a dry matter basis, possible evaporation of water during collections did not influence analyses. AMEI was calculated as ([energy intake energy lost in feces] - energy lost in urine), with energy measured in $\mathrm{kJ} / \mathrm{d}$.

In addition to AMEI, the efficiency by which ingested energy is converted to apparent digestible and metabolizable energy was determined. The apparent digestible energy coefficient (DEC, unitless proportion of energy) was calculated as ([energy intake - energy lost in feces]/energy intake), with energy measured in $\mathrm{kJ} / \mathrm{d}$. The apparent metabolizable energy coefficient (MEC, unitless proportion of energy) was calculated as AMEI/energy intake (Gluglielmo and Karasov 1996).

$B M R$.-Basalmetabolic rates (BMR) were determined by measuring $\mathrm{O}_{2}$ consumption of woodrats during the last day of control and juniper diet treatments. Woodrats were placed in open-circuit metabolic chambers (effective volume $500 \mathrm{~mL}$ ) at temperatures $\sim 27$ $28^{\circ} \mathrm{C}$. Chambers were covered in black paper to minimize disturbance of animals. The BMR of all woodrats were collected between 09:00 and 14:00. Because woodrats are nocturnal and the majority of food consumption occurs at the beginning of the dark cycle (approximately between 18:00 and 22:00), the measurement period constituted the time when specific dynamic action is minimal and woodrats are in the resting phase of their activity cycle (J. S. Sorensen, personal observation).

Each animal was acclimated to the metabolic chamber for $30 \mathrm{~min}$ before commencing measurements of BMR. $\mathrm{O}_{2}$ consumption was measured continuously for $30 \mathrm{~min}$ following the acclimation period. Measurements of BMR were taken following procedures in McLister et al. (2004).

The energetic cost of BMR was estimated by converting measurements of $\mathrm{O}_{2}$ consumption $\left(\mathrm{mL} \mathrm{O}_{2} / \mathrm{min}\right)$ to energy $(\mathrm{kJ} / \mathrm{d})$ using (liters of $\mathrm{O}_{2}$ consumed $/ \mathrm{d} \times 20.1$ $\mathrm{kJ} / \mathrm{L}$ oxygen) (Schmidt-Nielsen 1997). “Available energy" (kJ/d) for activities other than BMR was calculated as AMEI - BMR.

Locomotor activity.- Muntary locomotor activity was measured as the average activity during the $3 \mathrm{~d}$ at the end of control and creosote diet treatments. Distance $(\mathrm{km} / \mathrm{d})$, time spent running $(\mathrm{h} / \mathrm{d})$, and maximum speed $(\mathrm{km} / \mathrm{h})$ were recorded daily using event recorders (TOMO Cat Eye model CC-ST200; Performance Bicycle, Chapel Hill, North Carolina, USA) attached to wheels. Woodrats used the same wheel and event recorder throughout the experiment.

The energetic cost of voluntary wheel running in woodrats was estimated using the following equation for incremental cost of locomotion (ICL, $\mathrm{kJ} / \mathrm{km}$ ) from Garland (1983):

$$
\mathrm{ICL}=10.678 W^{0.70}
$$

where $W$ is body mass in kilograms. The daily cost of voluntary wheel running was then obtained by multiplying ICL by the daily distance run by each woodrat. Preliminary studies confirmed that woodrats conform to the costs of running used to generate the allometric equation for ICL (Taylor et al. 1970, Garland 1983).

"Surplus energy" ( $\mathrm{kJ} / \mathrm{d})$ was calculated as AMEI BMR - (daily cost of voluntary wheel running).

\section{Statistical analyses}

All statistical analyses were performed using JMP software for Macintosh (SAS Institute 2003). In general, analyses were performed using repeated measures ANOVA or ANCOVA with species (specialist vs. generalist) as the between-subjects effect and diet treatment (control vs. juniper) as the within-subjects effect. Covariates for ANCOVAs are specified for each analysis. Insignificant interactions between the covariate and main effects were removed from final analyses. Planned comparisons were performed using least squares means contrasts when significant interactions between species and diet treatment were detected or when there was both a significant effect of species and diet treatment. Sample size of analyses may vary for several reasons. All measures associated with urinary energy $(\mathrm{kJ} / \mathrm{g}, \mathrm{kJ} / \mathrm{d}, \mathrm{AMEI}, \mathrm{MEC}$, available energy, and surplus energy) were removed for one specialist on control diet because this animal did not excrete enough urine on control diet for bomb calorimetry. Available and surplus energy was removed from a different specialist because these values were negative and more than six standard deviations greater than mean values for specialists and generalists. In addition, this specialist was the only animal to lose $12 \%$ body mass during the creosote diet treatment. Daily energy excreted in the urine $(\mathrm{kJ} / \mathrm{d})$ was removed from another specialist on control diet because this value was more than eight standard deviations greater than mean values for specialists and generalists on control diet. Daily energy excreted and energy content of urine was removed for one generalist because these values were more than eight standard deviations greater than mean values for specialists and generalists on control diet.

Variables of AMEI.-Bodymass (g) was analyzed with a repeated-measures ANOVA. Dry matter intake $(\mathrm{g} / \mathrm{d})$ and energy intake $(\mathrm{kJ} / \mathrm{d})$ were analyzed separately with repeated-measures ANCOVAs with body mass as the covariate. The following variables were correlated with energy intake and were therefore analyzed by controlling for energy intake with a repeated-measures ANCOVA: total fecal and urinary energy excretion $(\mathrm{kJ} /$ d), dry matter output (g/d), and energy per gram feces or urine $(\mathrm{kJ} / \mathrm{g}$ dry mass). Metabolized energy intake $(\mathrm{kJ} / \mathrm{d})$ and the apparent digestible and metabolizable 
energy coefficients were analyzed with separate repeated-measures ANOVAs.

BMR.-Wholbody resting metabolic rate (BMR, $\mathrm{kJ} / \mathrm{d}$ ) was analyzed with a repeated-measure ANCOVA with body mass as the covariate. BMR and body mass were log-transformed prior to analysis. Available energy $(\mathrm{kJ} / \mathrm{d})$ was analyzed with a repeated-measures ANOVA.

Locomotor activity.-Distance, time, maximum speed, and surplus energy were analyzed separately with repeated measures ANOVAs. Distance and time were natural-log-transformed to normalize data. Because we were interested in the effect of available energy on locomotor activity, we performed independent linear regression analyses between locomotor activity (time and distance) and available energy for specialists and generalists on control and creosote diets.

\section{Physiological trade-offs associated with dietary specialization}

The physiological trade-offs associated with specialization were tested by comparing the performance of juniper specialists on their preferred plant vs. a novel plant and comparing these differences relative to the performance of generalists on the same diets. Body mass $(\mathrm{g})$ and gross food intake ( $\mathrm{g}$ dry mass/d) were selected as the parameters of performance for this comparison. Body mass and gross food intake were measured in the juniper specialist and generalist woodrats consuming PSMs from juniper (“juniper” experiment), or PSMs from creosote ("creosote" experiment). Feeding protocols were similar in both the juniper and creosote experiment, in that woodrats were given a control diet, followed by an acclimation diet, followed by $7 \mathrm{~d}$ of a diet containing either juniper foliage (following diet preparation in Dearing et al. 2000) or creosote resin. Measurements of body mass and dry matter intake during the juniper experiment was the same as outlined for the creosote experiment above. It was impossible to compare the relative dose and toxicity level of PSMs ingested between juniper and creosote diets because of the variety of PSMs present in each diet and the likelihood that some compounds are inert while others are toxic. However, selection of $7 \mathrm{~d}$ for both juniper and creosote diets standardized the time woodrats are exposed to PSMs from each plant.

Statistical analysis.-Becauseontrol diets differed slightly in composition between juniper and creosote experiments, we compared the performance of specialists and generalists between the two types of control diets. The following variables were compared between the two control diets using an ANOVA with each control diet as the main effect and body mass $(\mathrm{g})$, food intake $(\mathrm{g} / \mathrm{d})$, distance run $(\mathrm{km} / \mathrm{d})$, time spent running $(\mathrm{h} / \mathrm{d})$, maximum speed $(\mathrm{km} / \mathrm{h})$, and BMR $\left(\mathrm{mL} \mathrm{O}_{2} / \mathrm{min}\right)$ as the dependent variables.

Percent change in body mass $(\mathrm{g})$ and dry matter intake $(\mathrm{g} / \mathrm{d})$ were measured to compare performance of juniper specialists and generalists on juniper and creosote experiments. Percent change in body mass was calculated as the percent difference between body mass on the last day of control diet and last day of diet containing PSMs from juniper or creosote. Percent change in dry matter intake was calculated by the percent difference between the last three-day average at the end of control diet and diet containing PSM from juniper or creosote. Percent change in body mass and dry matter intake were compared between juniper and creosote experiments using a Tukey's honestly significant differences (hsd) procedure (Zar 1984).

\section{RESULTS}

\section{Performance on a diet containing novel PSMs}

Parameters of AMEI.-Thpresence of creosote resin in the diet affected body mass differently in specialists and generalist woodrats (Table 1). Overall, there was no main effect of species on body mass. However, specialists decreased body mass by $8 \%$ on creosote diet compared to control $(P<0.0001)$, whereas generalists had a similar body mass on control and creosote diets $(P=0.35)$ as indicated by a significant diet treatment and interaction effect. Body mass was positively correlated with dry matter intake and energy intake. When body mass was controlled, there was a significant main effect of species on dry matter intake. However, the species effect was driven primarily by differences between specialists and generalists on creosote diet. Dry matter intake did not differ between specialists and generalists on control diet $(P=0.13)$, but generalists consumed $\sim 35 \%$ more dry matter than specialists on creosote $\operatorname{diet}(P=0.04)$. Both specialists and generalists decreased dry matter intake on creosote diet compared to control. Similarly, there was a significant species and diet treatment effect on energy intake, but energy intake did not differ between specialists and generalists on control diet $(P=0.11)$, whereas generalists consumed $\sim 35 \%$ more energy than specialists on creosote $\operatorname{diet}(P=0.007$, Table 1$)$.

Ingestion of creosote diet influenced fecal and urinary excretion in specialists and generalists when energy intake was controlled (Table 1). Energy intake was positively correlated with total fecal energy, dry matter output of feces and urine, and energy per gram of urine, but not energy per gram of feces or total urinary energy. For fecal excretion, the intake of creosote decreased total fecal energy (Fig. 1) and dry matter output of feces, and increased the apparent digestible energy coefficient (DEC), but did not alter energy content of feces (Table 1). For urinary excretion, the intake of creosote increased total urinary energy, dry matter output and energy per gram urine. Woodrats excreted up to five times more total energy in the urine on creosote diet compared to control when energy intake was controlled (Fig. 1). There was no significant species effect 

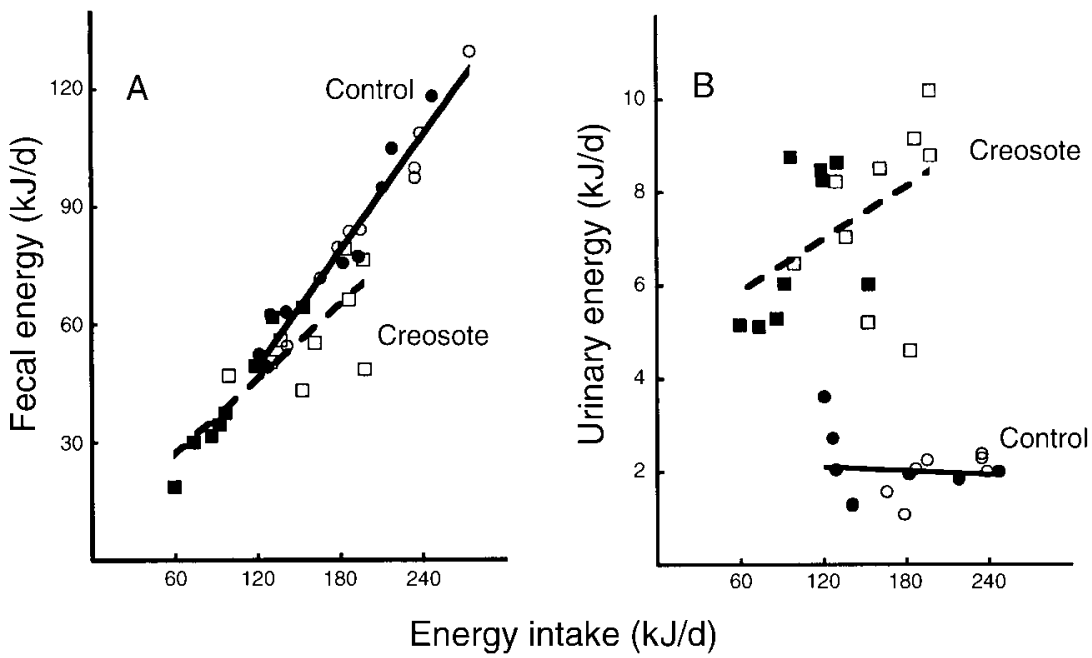

FIG. 1. The energy excreted in (A) feces and (B) urine plotted against energy intake in woodrats on a control diet (solid line) and diet containing $2 \%$ creosote resin (dashed line). Circles indicate control diet, and squares indicate juniper diet. Open symbols represent specialist woodrats, and filled symbols represent generalist woodrats. Because there was no significant species effect for fecal and urinary energy ANCOVAs, specialists and generalists were combined for each diet regression. Linear regression results: (A) control diet, $y=-9.5+0.49 x, P<0.0001, R^{2}=0.95$; juniper diet, $y=8.2+0.3 x, P<$ $0.0001, R^{2}=0.70$; (B) control diet, $y=2.3+x, P=0.70, R^{2}=0.01$; juniper diet, $y=4.7+0.02 x, P=0.05, R^{2}=0.21$.

or species by diet treatment interaction for any parameter of fecal or urinary excretion.

AMEI was negatively impacted by creosote intake in woodrats (Table 1). Specialists had lower AMEI than generalists on control and creosote diets. Woodrats had between $17 \%$ and $40 \%$ less AMEI on a creosote diet than control (Fig. 2). However, the apparent metabolizable energy coefficient (MEC) did not differ between species or diet treatment (Table 1).

\section{Energy expenditure}

BMR.-BMRwas positively correlated with body mass (Table 2). When body mass was controlled, BMR did not differ between specialists and generalists on control or creosote diets (Fig. 2). There was also no diet treatment effect or interaction on BMR in woodrats.

Overall, specialists had less available energy (AMEI - BMR) for activities such as voluntary wheel running than generalists (Table 2). Although there was also a significant diet treatment effect on available energy, only specialists decreased available energy on creosote diet. Specialists had one-quarter the energy on creosote diet relative to control diet $(P=0.007)$, whereas generalists had similar amounts of available energy on control and creosote diets $(P=0.13)$.

Locomotor activity.-O Overallwoodrats ran less and spent less time running when consuming creosote diets than control (Table 2). Specialists and generalists did not differ in the distance run, time spent running, or maximum speed. Although there was a significant diet treatment effect on distance, this effect was driven primarily by generalists. Generalists reduced distance run by $53 \%$ on creosote diet compared to control $(P=$
$0.004)$, whereas specialists ran the same distance on control and creosote diets $(P=0.17)$. Specialists and generalists spent less time running when consuming the creosote diet than control diet. Specialists and generalists also had lower maximum speeds on creosote diet than control. There was no species-by-diet interaction for distance, time spent running, or maximum speed.

On control diet, locomotor activity was positively correlated with available energy in both specialists (distance, $F_{1,6}=5.68, P=0.05, R^{2}=0.49$; time, $F_{1,6}$ $=7.12, P=0.04, R^{2}=0.54$ ) and generalists (distance, $F_{1,7}=22.27, P=0.002, R^{2}=0.76$; time, $F_{1,7}=13.63$, $\left.P=0.008, R^{2}=0.66\right)$. In contrast, locomotor activity was not correlated with available energy on creosote diet for either specialists (distance, $F_{1,7}=0.95, P=$ $0.37, R^{2}=0.14$; time, $F_{1,7}=0.95, P=0.37, R^{2}=$ 0.14 ) or generalists (distance, $F_{1,7}=2.52, P=0.16$, $R^{2}=0.26$; time, $\left.F_{1,7}=2.39, P=0.17, R^{2}=0.25\right)$.

Creosote intake affected surplus energy (AMEI BMR - voluntary wheel running) differently in specialists and generalists (Fig. 2; Table 2). Overall, species did not differ in surplus energy. Although there was a significant effect of diet treatment on surplus energy, this effect was driven primarily by specialists. Specialists had one-sixth the surplus energy when consuming a creosote diet compared to control $(P=0.005)$ whereas, generalists did not change surplus energy on control and creosote diets $(P=0.48)$. There was a marginally significant species by diet treatment interaction for surplus energy.

\section{Physiological trade-offs associated with dietary specialization}

There was no difference in performance between the control diets from juniper and creosote experiments in 
TABLE 1. (A) Means and (B) summary of ANOVAs and ANCOVAs for body mass, dry matter intake, energy intake, parameters of fecal and urinary excretion, apparent digestible energy coefficient (DEC), apparent metabolizable energy intake (AMEI), and apparent metabolizable energy coefficient (MEC) in specialist and generalist woodrats on control and creosote diet.

\begin{tabular}{|c|c|c|c|c|}
\hline \multicolumn{5}{|l|}{ A) Means } \\
\hline \multirow[b]{3}{*}{ Variable } & \multicolumn{4}{|c|}{ Mean $\pm 1 \mathrm{SE}$} \\
\hline & \multicolumn{2}{|c|}{ Specialist } & \multicolumn{2}{|c|}{ Generalist } \\
\hline & Control diet & Creosote diet & Control diet & Creosole diet \\
\hline Body mass (g) & $180.3 \pm 9.67$ & $165.7 \pm 10.23$ & $185.5 \pm 5.09$ & $182.9 \pm 5.01$ \\
\hline Dry matter intake $(\mathrm{g} / \mathrm{d})$ & $10.6 \pm 0.94$ & $5.9 \pm 0.57$ & $12.5 \pm 0.86$ & $9.2 \pm 0.65$ \\
\hline Energy intake $(\mathrm{kJ} / \mathrm{d})$ & $174.5 \pm 15.44$ & $103.6 \pm 9.86$ & $205.71 \pm 14.14$ & $160.5 \pm 11.36$ \\
\hline Fecal energy $(\mathrm{kJ} / \mathrm{d})$ & $77.5 \pm 7.95$ & $41.9 \pm 5.10$ & $89.9 \pm 7.31$ & $58.0 \pm 4.33$ \\
\hline Fecal output $(\mathrm{g} / \mathrm{d})$ & $4.6 \pm 0.46$ & $2.4 \pm 0.30$ & $5.4 \pm 0.45$ & $3.38 \pm 0.27$ \\
\hline Energy per gram feces $(\mathrm{kJ} / \mathrm{g})$ & $16.8 \pm 0.20$ & $17.1 \pm 0.19$ & $16.8 \pm 0.05$ & $17.2 \pm 0.14$ \\
\hline DEC & $0.56 \pm 0.01$ & $0.60 \pm 0.01$ & $0.57 \pm 0.01$ & $0.63 \pm 0.02$ \\
\hline Urinary energy $(\mathrm{kJ} / \mathrm{d})$ & $2.2 \pm 0.28$ & $6.9 \pm 0.54$ & $1.9 \pm 0.15$ & $7.6 \pm 0.63$ \\
\hline Urinary output $(\mathrm{g} / \mathrm{d})$ & $0.67 \pm 0.05$ & $0.78 \pm 0.08$ & $0.66 \pm 0.07$ & $0.87 \pm 0.07$ \\
\hline Energy per gram urine $(\mathrm{kJ} / \mathrm{g})$ & $4.1 \pm 0.58$ & $9.0 \pm 0.25$ & $3.2 \pm 0.18$ & $8.7 \pm 0.17$ \\
\hline AMEI $(\mathrm{kJ} / \mathrm{d})$ & $91.6 \pm 8.46$ & $54.8 \pm 4.70$ & $113.7 \pm 6.68$ & $94.9 \pm 9.25$ \\
\hline MEC & $0.54 \pm 0.01$ & $0.54 \pm 0.01$ & $0.55 \pm 0.01$ & $0.58 \pm 0.03$ \\
\hline
\end{tabular}

B) Summary of ANOVAs and ANCOVAs

ANOVA/ANCOVA

\begin{tabular}{|c|c|c|c|}
\hline \multirow[b]{2}{*}{ Source of variation } & & & \\
\hline & $F$ & $\mathrm{df}$ & $P$ \\
\hline \multicolumn{4}{|l|}{ Body mass } \\
\hline Species & 1.03 & 1,16 & 0.33 \\
\hline Diet & 20.94 & 1,16 & 0.0003 \\
\hline Species $\times$ diet & 10.38 & 1,16 & 0.005 \\
\hline \multicolumn{4}{|l|}{ Dry matter intake } \\
\hline Species & 5.06 & 1,16 & 0.04 \\
\hline Diet & 45.76 & 1,15 & $<0.0001$ \\
\hline Species $\times$ diet & 0.68 & 1,15 & 0.42 \\
\hline Covariate (body mass) & 5.26 & 1,15 & 0.04 \\
\hline \multicolumn{4}{|l|}{ Energy intake } \\
\hline Species & 5.18 & 1,16 & 0.04 \\
\hline Diet & 35.20 & 1,15 & $<0.0001$ \\
\hline Species $\times$ diet & 0.96 & 1,15 & 0.34 \\
\hline Covariate (body mass) & 5.39 & 1,15 & 0.03 \\
\hline \multicolumn{4}{|l|}{ Fecal energy } \\
\hline Species & 3.27 & 1,16 & 0.09 \\
\hline Diet & 5.06 & 1,15 & 0.04 \\
\hline Species $\times$ diet & 2.27 & 1,15 & 0.15 \\
\hline Covariate (energy intake) & 151.4 & 1,15 & $<0.0001$ \\
\hline \multicolumn{4}{|l|}{ Fecal output } \\
\hline Species & 3.62 & 1,16 & 0.08 \\
\hline Diet & 6.83 & 1,15 & 0.02 \\
\hline Species $\times$ diet & 2.85 & 1,15 & 0.11 \\
\hline Covariate (energy intake) & 160.8 & 1,15 & $<0.0001$ \\
\hline \multicolumn{4}{|l|}{ Energy per gram feces } \\
\hline Species & 0.08 & 1,16 & 0.78 \\
\hline Diet & 3.56 & 1,15 & 0.08 \\
\hline Species $\times$ diet & 0.28 & 1,15 & 0.61 \\
\hline Covariate (energy intake) & 0.04 & 1,15 & 0.84 \\
\hline \multicolumn{4}{|l|}{$\mathrm{DEC}$} \\
\hline Species & 1.08 & 1,16 & 0.32 \\
\hline Diet & 14.5 & 1,16 & 0.002 \\
\hline Species $\times$ diet & 0.47 & 1,16 & 0.50 \\
\hline \multicolumn{4}{|l|}{ Urinary energy } \\
\hline Species & 0.16 & 1,16 & 0.69 \\
\hline Diet & 97.61 & 1,12 & $<0.0001$ \\
\hline Species $\times$ diet & 0.65 & 1,12 & 0.44 \\
\hline Covariate (energy intake) & 2.16 & 1,12 & 0.17 \\
\hline
\end{tabular}


TABle 1. Continued.

\begin{tabular}{|c|c|c|c|}
\hline \multirow[b]{2}{*}{ Source of variation } & \multicolumn{3}{|c|}{ ANOVA/ANCOVA } \\
\hline & $F$ & $\mathrm{df}$ & $P$ \\
\hline \multicolumn{4}{|l|}{ Urinary output } \\
\hline Species & 1.62 & 1,16 & 0.22 \\
\hline Diet & 19.25 & 1,15 & 0.0005 \\
\hline Species $\times$ diet & 0.07 & 1,15 & 0.80 \\
\hline Covariate (energy intake) & 13.0 & 1,15 & 0.003 \\
\hline \multicolumn{4}{|l|}{ Energy per gram urine } \\
\hline Species & 0.07 & 1,16 & 0.79 \\
\hline Diet & 185.0 & 1,13 & $<0.0001$ \\
\hline Species $\times$ diet & 4.12 & 1,13 & 0.06 \\
\hline Covariate (energy intake) & 5.51 & 1,13 & 0.04 \\
\hline \multicolumn{4}{|l|}{ AMEI } \\
\hline Species & 11.75 & 1,16 & 0.004 \\
\hline Diet & 31.58 & 1,15 & $<0.0001$ \\
\hline Species $\times$ diet & 3.0 & 1,15 & 0.10 \\
\hline \multicolumn{4}{|l|}{ MEC } \\
\hline Species & 2.55 & 1,15 & 0.13 \\
\hline Diet & 0.42 & 1,15 & 0.53 \\
\hline Species $\times$ diet & 1.57 & 1,15 & 0.23 \\
\hline
\end{tabular}

Notes: "Species" is the between-subjects effect, and "diet" is the within-subjects effect. Apparent digestible energy coefficient $($ DEC $)=([$ energy intake - fecal energy $]$ /energy intake $)$. Apparent metabolizable energy intake $(\mathrm{AMEI})=($ energy intake $)-($ fecal energy $)-($ urinary energy). Apparent metabolizable energy coefficient (MEC) $=\mathrm{AMEI} /($ energy intake).

woodrats. Specialists and generalists each had similar body mass, dry matter intake, wheel running activity (distance, time, maximum speed), and BMR on both types of control diets (Tables 1 and 2; see also Sorensen et al. 2005).

Juniper specialists performed better on the juniper diet containing PSMs that are naturally consumed than on a creosote diet containing novel PSMs, whereas the performance of generalists was impacted similarly by naturally consumed and novel PSMs. Specialists in-

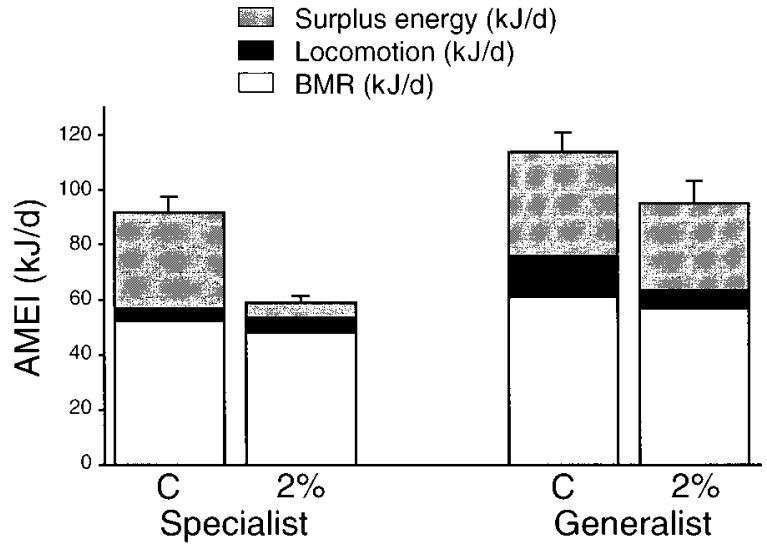

FIG. 2. Apparent metabolizable energy intake (AMEI) in specialist and generalist woodrats on control diet (C) and diet containing creosote resin $(2 \%)$. AMEI is partitioned into the energy expended on basal metabolic rate (BMR), voluntary wheel running (locomotion), and the surplus energy (AMEI - BMR - [voluntary wheel running]) available for activities such as reproduction, thermoregulation, and immunocompetency. creased body mass and dry matter intake on a juniper diet, but decreased body mass and dry matter intake on a creosote diet. Generalists decreased body mass and dry matter intake to a similar extent on juniper and creosote. Moreover, specialists performed better than generalists on juniper diet, but worse than generalists on a creosote diet (Fig. 3). On the juniper diet, specialists increased body mass and dry matter intake, whereas generalists decreased these variables. Although both specialists and generalists decreased body mass and dry matter intake on a creosote diet, specialists decreased body mass to a greater extent than generalists.

\section{DISCUSSION}

We hypothesized that the ingestion of a diet containing novel PSMs, creosote resin, would negatively impact the performance of woodrats. Moreover, we hypothesized that the juniper specialist would be more impacted by the intake of novel PSMs in creosote diet than the generalist. Both hypotheses were supported. Specialists reduced body mass, intake, and AMEI and had less surplus energy available for activities other than BMR and voluntary wheel running when consuming a creosote diet compared to control. Generalists maintained body mass, reduced intake and AMEI, but to a lesser extent than specialists, and maintained surplus energy on a creosote diet compared to control. Generalists had nearly six times the surplus energy of specialists on creosote diets, primarily because specialists consumed less creosote diet than generalists. These results are in stark contrast to the comparisons between specialists and generalists consuming PSMs 
TABLE 2. (A) Means and (B) summary of ANOVAs and ANCOVAs for basal metabolic rate (BMR), available energy, locomotor activity, and surplus energy for specialist and generalist woodrats on control and creosote diet.

\begin{tabular}{|c|c|c|c|c|}
\hline \multicolumn{5}{|l|}{ A) Means } \\
\hline \multirow[b]{3}{*}{ Variable } & \multicolumn{4}{|c|}{ Mean $\pm 1 \mathrm{SE}$} \\
\hline & \multicolumn{2}{|c|}{ Specialist } & \multicolumn{2}{|c|}{ Generalist } \\
\hline & Control diet & Creosote diet & Control diet & Creosote diet \\
\hline $\mathrm{BMR}(\mathrm{mL} \mathrm{O} / \mathrm{min})$ & $1.80 \pm 0.12$ & $1.66 \pm 0.16$ & $2.12 \pm 0.16$ & $1.96 \pm 0.08$ \\
\hline Available energy $(\mathrm{kJ} / \mathrm{d})$ & $39.4 \pm 7.36$ & $9.9 \pm 0.08$ & $52.5 \pm 9.83$ & $38.3 \pm 9.36$ \\
\hline Distance $(\mathrm{km} / \mathrm{d})$ & $1.5 \pm 0.50$ & $1.7 \pm 0.75$ & $4.5 \pm 1.02$ & $2.1 \pm 0.59$ \\
\hline Time $(\mathrm{h} / \mathrm{d})$ & $0.6 \pm 0.19$ & $0.5 \pm 0.22$ & $1.4 \pm 0.30$ & $0.6 \pm 0.16$ \\
\hline Maximum speed $(\mathrm{km} / \mathrm{h})$ & $9.4 \pm 0.36$ & $7.6 \pm 0.57$ & $9.9 \pm 0.69$ & $8.8 \pm 0.45$ \\
\hline Surplus energy $(\mathrm{kJ} / \mathrm{d})$ & $35.1 \pm 5.80$ & $5.6 \pm 2.36$ & $37.5 \pm 7.46$ & $31.4 \pm 8.58$ \\
\hline
\end{tabular}

B) Summary of ANOVAs and ANCOVAs

\begin{tabular}{|c|c|c|c|}
\hline \multirow{2}{*}{ Source of variation } & \\
\hline & $F$ & $\mathrm{df}$ & $P$ \\
\hline \multicolumn{4}{|l|}{$\overline{\mathrm{BMR}}$} \\
\hline Species & 2.38 & 1,16 & 0.14 \\
\hline Diet & 0.66 & 1,15 & 0.43 \\
\hline Species $\times$ diet & 0.08 & 1,15 & 0.78 \\
\hline Covariate (body mass) & 13.46 & 1,15 & 0.002 \\
\hline \multicolumn{4}{|l|}{ Available energy } \\
\hline Species & 4.89 & 1,15 & 0.04 \\
\hline Diet & 11.30 & 1,15 & 0.004 \\
\hline Species $\times$ diet & 1.40 & 1,15 & 0.26 \\
\hline \multicolumn{4}{|l|}{ Distance } \\
\hline Species & 3.20 & 1,16 & 0.09 \\
\hline Diet & 11.83 & 1,16 & 0.003 \\
\hline Species $\times$ diet & 1.99 & 1,16 & 0.18 \\
\hline \multicolumn{4}{|l|}{ Time } \\
\hline Species & 2.55 & 1,16 & 0.13 \\
\hline Diet & 15.46 & 1,16 & 0.001 \\
\hline Species $\times$ diet & 0.33 & 1,16 & 0.57 \\
\hline \multicolumn{4}{|l|}{ Maximum speed } \\
\hline Species & 1.85 & 1,16 & 0.19 \\
\hline Diet & 12.71 & 1,16 & 0.003 \\
\hline Species $\times$ diet & 0.76 & 1,16 & 0.40 \\
\hline \multicolumn{4}{|l|}{ Surplus energy } \\
\hline Species & 3.82 & 1,15 & 0.07 \\
\hline Diet & 8.21 & 1,15 & 0.01 \\
\hline Species $\times$ diet & 3.54 & 1,15 & 0.08 \\
\hline
\end{tabular}

Notes: "Species" is the between-subjects effect, and "diet" is the within-subjects effect. Available energy $=$ AMEI- (energy expended on BMR). Surplus energy = AMEI-(energy expended on BMR)-(energy expended on voluntary wheel running.

FIG. 3. Percentage change in (A) body mass and (B) dry matter intake for specialists and generalists in juniper and creosote experiments. Different letters represent significant differences between means using Tukey's honestly significant differences (hsd) procedure (Zar 1984). Error bars indicate 1 SE.

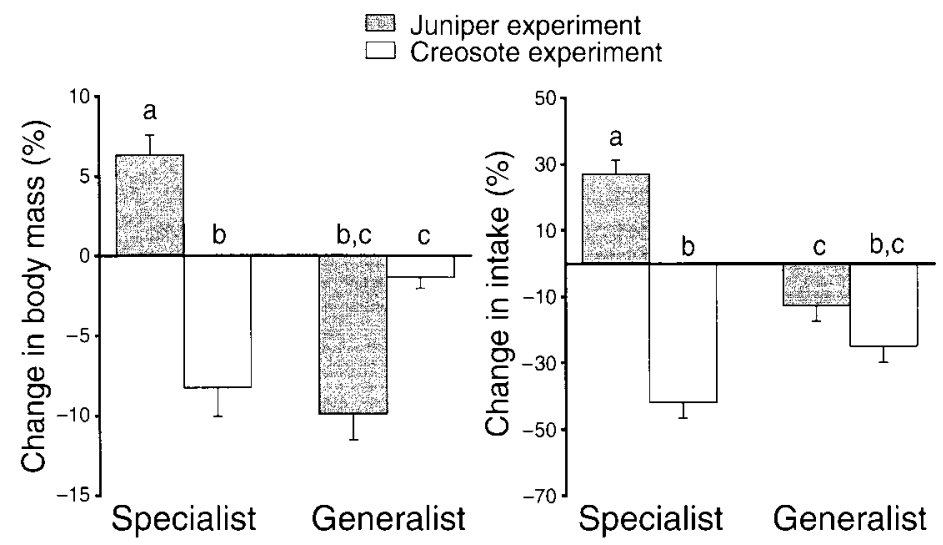


from their natural diet (juniper; see Sorensen et al. 2005) and suggest a physiological trade-off associated with dietary specialization. In the subsequent paragraphs, we expand on the different energetic responses of juniper specialists and generalists consuming a diet containing creosote resin and compare these results to their performance on a diet containing juniper.

\section{Apparent metabolizable energy intake}

Both theoretical and empirical studies suggest that maximization of AMEI is critical for the survival, reproductive success and distribution of animals (Karasov 1986, Song and Wang 2002). A reduction in AMEI of woodrats consuming creosote could therefore be detrimental to fitness because it limits the energy available for activities such as maintenance, activity, reproduction, and growth. Both gross food intake and the efficiency by which energy is absorbed from food and subsequently lost in urine can have a direct influence on AMEI. Several studies have demonstrated that intake is negatively correlated with the concentration of PSMs in the diet (Foley et al. 1999, Stapley et al. 2000, Wiggins et al. 2003). AMEI may therefore be limited by the maximum tolerable dose of PSM that can be ingested. It is also well documented that PSMs can decrease AMEI by lowering the efficiency of energy conversion through increased excretion of energy in the urine and feces (Foley and McArthur 1994, Guglielmo and Karasov 1996, Silverstein et al. 1996, Mangione et al. 2001, Song et al. 2002). The subsequent sections describe the relative importance of excreted energy and gross intake on AMEI in specialist and generalist woodrats consuming PSMs from creosote.

Specialists and generalists excreted substantial quantities of energy in the urine when consuming creosote diet, indicating that the PSMs in creosote are absorbed, detoxified, and represent an energetic cost to woodrats. The ingestion and absorption of PSMs results in excretion of energy rich detoxification metabolites in the urine (Foley 1987, Guglielmo and Karasov 1996). Specifically, other species of woodrats (Neotoma lepida) excrete large quantities of glucuronic acid, a derivative of endogenous glucose, when consuming creosote resin (Mangione et al. 2001). Moreover, the predominant PSM in creosote, NDGA, is primarily detoxified via glucuronic acid conjugation in mice (Lambert et al. 2002). Therefore, a portion of the total energy lost in the urine of specialist and generalist woodrats fed creosote diet may have been attributable to usable endogenous energy (i.e., glucose). Regardless of source, the total energy loss associated with the intake of PSMs may represent a significant energetic cost in mammalian herbivores. For example, energy excreted in the urine of woodrats consuming creosote diets was 13 $14 \%$ of the cost of BMR in specialists and generalists, but was only $4 \%$ of BMR in woodrats on control diet. The relative cost of urinary energy loss in N. stephensi and $N$. albigula woodrats consuming creosote was com- parable to the proportion of BMR that was allocated to pregnancy in mammals (Randolph et al. 1977).

Although energy excreted in the urine was high and contributed to a reduction in AMEI, the major factor that influenced AMEI was gross food intake. A reduction in AMEI was not due to a reduction in the efficiency of utilizing energy on a creosote diet. Apparent metabolizable energy coefficients (MEC) were similar on control and creosote diets for both specialists and generalists and did not differ between species on either diet. MEC is dependent on both urinary and fecal energy losses, with fecal energy being a greater contributor. The larger decrease in fecal energy $(\sim 33 \mathrm{~kJ} / \mathrm{d})$ on a creosote diet compensated for the relatively small contribution of increased urinary energy $(\sim 5 \mathrm{~kJ} / \mathrm{d})$, resulting in a constant MEC on control and creosote diets. Specialists therefore reduced AMEI more than generalists on a creosote diet, not due to a reduction in MEC, but instead due to a relative decrease in dry matter intake that was nearly twice as much in specialists compared to generalists. These comparisons suggest that AMEI was regulated by the maximum tolerable level of creosote that can be ingested. Moreover, results indicate that dietary specialist may be limited by the intake of a novel plant to a greater extent than generalists.

There are several factors that could explain why specialists exhibit lower tolerable intake of creosote resin than generalists. Tolerance is often limited by the physiological capacity to detoxify and eliminate PSMs from the body (Lawler et al. 1998, Boyle et al. 1999a, Stapley et al. 2000, Mangione et al. 2001, Pass et al. 2001, 2002). Several studies indicate that specialist herbivores are more efficient at eliminating PSMs in their preferred diet than generalists (Sorensen and Dearing 2003, Sorensen et al. 2004) and may have high constitutive detoxification activity (Berenbaum and Zangerl 1994; Lamb et al., in press). However, these elimination mechanisms may be specific and/or most efficient at eliminating the PSMs routinely encountered in the preferred diet of the specialist. For example, the highly specialized koala primarily utilizes oxidation pathways over conjugation to detoxify the terpenes in its preferred plant, Eucalyptus, compared to generalized marsupial folivores (Boyle et al. 1999a, b). Oxidation reactions are considered to be less energetically expensive, but occur at slower rates than conjugation reactions (Klaassen 2001). Therefore, greater reliance on oxidation over conjugation may require a downregulation or loss of conjugation enzymes. In support, recent work suggests that juniper specialists have lower levels of mRNA for glucuronidation enzymes, lower rates of activity for glucuronidation, but higher oxidation activity than lab rats (Lamb et al., 2004). Because NDGA is primarily detoxified by glucuronidation (Lambert et al. 2002), limited glucuronidation activity in specialists may constrain their capacity to detoxify creosote resin. In addition, the oxidation of several 
compounds results in the formation of reactive intermediates that would prove toxic to mammals without subsequent conjugation (Rinaldi et al. 2002). Limited conjugation capacity may therefore reduce the breadth of PSMs, including those in creosote, that can be readily detoxified and subsequently limit the quantity and diversity of plants that can be consumed by specialist woodrats.

\section{Energy expenditure}

On creosote diets, gross energy intake is restricted by the ability to ingest resin. Woodrats should compensate for reduced intake and increased energy losses on a creosote diet by reducing energy expenditure. Energy expenditure can be minimized through reduced BMR and/or reduced activity. BMR is considered a somewhat plastic trait that can be down-regulated in homeotherms to cope with energy limitations (Hill et al. 1985, Munch et al. 1993, Deerenberg et al. 1998). For example, several species of birds and mammals employ regulated hypothermia resulting in a reduction in BMR and body temperature (Carpenter and Hixon 1988, Gordon 1993, McNab 2002). Locomotion is an additional activity that can be regulated to conserve energy. For example, reduced locomotor activity is thought to explain how animals can maintain food intake and BMR during lactation (Randolph et al. 1977, Wade and Schneider 1992, McLean and Speakman 1999). Reduced energy expenditure will maximize the energy available for activities essential to fitness, such as reproduction. Woodrats consuming creosote resin did not reduce BMR, but did decrease locomotor activity compared to control diet. The following sections discuss the energetic consequences of energy expended on BMR and voluntary wheel running and compare energy expenditure between specialist and generalist woodrats.

$B M R$. - Whole-bodyBMR was not impacted by the intake of creosote in woodrats when body mass was controlled. These data suggest that the intake and detoxification of PSMs in creosote was not metabolically expensive in woodrats. However, increased energy excreted in the urine does suggest that a metabolic load was imposed on woodrats consuming PSMs from creosote. This metabolic load may not have altered BMR in woodrats either because the energetic cost of conjugation and excretion of metabolites was relatively low or because animals reduced some other component of BMR such as the immune system. These data add to the ambiguous support for the metabolic load hypothesis in mammalian herbivores. Three separate studies have shown an increase in metabolic rate when mammalian herbivores consume diets containing PSMs (Thomas et al. 1988, Iason and Murray 1996, Bozinovic and Novoa 1997). In contrast, a separate study found that the two species used in the present study, N. stephensi and $N$. albigula, decreased metabolic expenditure when consuming diets containing juniper foliage
(Boyle and Dearing 2003). In the present study, $N$. stephensi and $N$. albigula maintained metabolic expenditure when consuming PSMs from creosote. Differences among studies could represent species differences and/or differences between the type and diversity of PSM used.

Studies investigating the metabolic load hypothesis may also have differed in results because metabolic expenditure was not placed within the context of energy budgets. Mammals demonstrate remarkable phenotypic plasticity in the allocation of energy to BMR. This plasticity is thought to demonstrate an ability to conserve energy for important activities such as reproduction and thermoregulation (Hill et al. 1985, Carpenter and Hixon 1988, McNab 2002). For example, lab rats reduced metabolism, not associated with specific dynamic action, by $\sim 17 \%$ when food was restricted to $75 \%$ of maintenance (Hill et al. 1985). The inability to reduce metabolic expenditure on creosote diet when AMEI decreased may represent a cost of consuming PSMs because it reduced the pool of energy available for other activities. If the quantity of surplus energy on control diet (specialist, $35.1 \mathrm{~kJ} / \mathrm{d}$; generalist, $36.5 \mathrm{~kJ} / \mathrm{d}$ ) is considered the maximum energy required to perform daily activities, we can calculate the percent reduction in BMR that is necessary to maintain body mass in specialists and generalists. Specialists would require at least a $50 \%$ reduction in $\mathrm{BMR}$ to maintain body mass on the creosote diet, whereas generalists only need to reduce BMR by $6 \%$. These differences emphasize the energetic consequence of consuming novel PSMs and underscore the lower performance of specialists consuming novel PSMs compared to generalists.

Locomotor activity.-Decreasedocomotor activity of woodrats on creosote diet may represent a consequence of constraints on energy availability and/or be a pharmacological consequence of PSM ingestion. Locomotion is an expensive activity (Karasov 1986, Kenagy et al. 1989, Koteja et al. 1999) that may be regulated to reduce energy expenditure during periods of energy limitations (Randolph et al. 1977, Wade and Schneider 1992). For example, reduced locomotor activity in trout was directly related to the depletion of glucose stores associated with the process of detoxification (Handy et al. 1999). Alternatively, but not mutually exclusive, locomotor activity may be compromised due to the pharmacological effects of ingested compounds. For example, wild and laboratory rodents decreased locomotor activity immediately following exposure to a large dose of organophosphate pesticides and anticholinergic compounds (Gordon and Padnos 2002, Dell'Omo et al. 2003).

The locomotor activity of woodrats consuming creosote diet suggests that reduced voluntary wheel running may be associated with both energy limitations and toxicity. Despite a strong correlation between activity and available energy of woodrats on control diet, 
there was no relationship between available energy and distance or time on creosote diet. In addition, changes in maximum speed further suggest that reduced locomotor activity was partially related to toxicity. Both specialists and generalists reduced maximum speed when consuming creosote PSMs, which is suggestive of toxic effects.

Reduced locomotor activity in response to PSM intake may have substantial ecological consequences. Although voluntary wheel running is not the only activity that demands energy, such locomotor activity is critical for foraging, defending territories, escaping predators, and finding mates (Swingland and Greenwood 1983, Karasov 1986, Weis et al. 2001). A reduction in the time devoted to locomotion when mammals consume PSMs may be important to the fitness of mammalian herbivores in nature. The consumption of low quality foods, such as creosote and juniper, that are high in fiber and PSMs require higher intake rates and therefore should require increased locomotion during foraging to find adequate quantities of plant matter. However, consumption rates would be constrained if activity is depressed by the intake of PSMs. Compromised activity may also exacerbate the energetic costs of processing PSMs by limiting the travel distances required to find higher quality forage in the patchily distributed habitat of these woodrat species (Dial and Czaplewski 1990). Although much work is needed to identify the implications of compromised locomotion in natural populations of woodrats, our data provide strong evidence that the intake of PSMs negatively influences locomotion in wild mammalian herbivores.

\section{Physiological trade-offs associated with dietary specialization}

Determining whether physiological trade-offs exist between animals that consume small quantities of a variety of PSMs (generalist) vs. those that consume large quantities of a limited variety of PSMs (specialist) is central to understanding the constraints of dietary specialization. Ecological theory predicts that specialists have highly modified, reduced, or lost traits, whereas generalists are predicted to have a wider, less specific breadth of traits (Futuyma and Moreno 1988). This comparison between a juniper specialist and a generalist consuming juniper and a novel diet provides the first evidence that physiological trade-offs associated with dietary specialization may exist in mammalian herbivores. Although rigorous testing of an adaptive hypothesis for the evolution of dietary specialization requires the comparison of many specialist-generalist pairs, these findings are in agreement with predictions and support similar studies performed on specialist and generalist insects (Futuyma and Moreno 1988, Berenbaum and Zangerl 1994, Mackenzie 1996). Relative to generalists, juniper specialists had higher intake levels of their preferred plant, juniper, but consumed lower levels of a novel plant species, creosote.
Our data, combined with recent literature, demonstrate that juniper specialists may have a higher capacity to eliminate PSMs from juniper than generalists, but may lack these abilities when faced with novel PSMs. For example, juniper specialists excreted a higher proportion of ingested PSMs from juniper than generalists, indicating that specialists possess mechanisms that minimize the absorption of juniper PSMs (Sorensen and Dearing 2003, Sorensen et al. 2004). A greater capacity to regulate the absorption of PSMs in specialists compared to generalist may be due to genetic differences or differences in exposure to juniper during early development (i.e., in utero, during lactation). Although elimination capacity for PSMs in creosote has not been directly investigated, the low intake of creosote by specialists compared to generalists suggests that specialists may have a lower capacity to eliminate creosote PSMs than generalists. For example, the mechanisms that regulate the absorption of PSMs in juniper may not be functional for the PSMs in creosote, forcing specialists to rely on detoxification mechanisms that are less efficient than that used by generalists. In support, the major PSM in creosote, NDGA, requires glucuronidation for elimination (Lambert et al. 2002) and recent work suggests that specialists may have an overall lower capacity to glucuronidate PSMs than generalist (Sorensen et al. 2005). Further work is needed to identify the relationship between constraints on specific detoxification and elimination mechanisms and the intake of novel PSMs. Moreover, given the limitations of a single, two species comparison in testing an adaptive hypothesis, these results emphasize a need for further studies using additional novel PSMs and specialistgeneralist mammalian herbivores.

Reduced intake of novel plants by a dietary specialist compared to a generalist has several ecological and evolutionary implications. If specialists possess a limited capacity to consume a diversity of novel plants, they may be less resilient to the ubiquitous changes in the environment than generalists. Livestock grazing, human recreation, timber cutting, drought-induced fires, introduction of invasive species, and climate change can alter the abundance and distribution of the plant species preferred by specialists (McDonald and Brown 1992). The results from the creosote diet indicate that juniper specialists were negatively impacted by a diet containing as little as $20 \%$ creosote $(\sim 2 \%$ creosote resin). For example, specialists consuming $20 \%$ creosote in their diet are expected to experience a deficit of energy once energy has been allocated to BMR and locomotion (i.e., surplus energy; Fig. 2). This energy deficit would result in significant body mass loss and no energy available for other activities such as grooming, alertness, or, more importantly, immunocompetency, reproduction, and thermoregulation. If specialists are unable to obtain alternative food, increase tolerance to novel PSMs or reduce BMR and activity they may be forced to compromise an already 
low reproductive output (Vaughan and Czaplewski 1985). Generalists, on the other hand, may be less impacted by changes in plant availability. Generalists are accustomed to handling a diverse set of PSMs, as supported by their general response to both juniper and creosote and their varied diet in the field (Dial 1988). Generalists may also be less affected by changes in plant availability because they can obtain alternative food resources better than specialists due to a generalist foraging strategy and ability to out-compete specialists (Howe 1978, Dial 1988). Understanding the way in which mammals will respond to natural and novel chemical challenges and the constraints on these responses may allow biologists to predict which animals will be most affected by unavoidable changes in plant availability, increased PSM concentrations, and the ubiquity of environmental contaminants.

\section{ACKNOWLEDGMENTS}

We thank B. Hudson and employees of Wupatki National Monument Visitor Center for assistance and accommodations during our trapping sessions. H. Baldwin, R. Boyle, D. Green, C. Heidelberger, and S. O'Grady assisted in collecting woodrats in the field. Y. Al-Sheikh, E. van Dijk, J. Grose, E. Heward, A. Knudson, E. McLachlan, S. Rogers, L. Santos, C. A. Turnbull, A. Walters, and M. Wong assisted in experimental procedures and animal husbandry and were supported by the University of Utah BioURP and NSF REU. Research was supported by NSF IBN-0079865 and 0236402, American Society of Mammalogists Grant-in-Aid of Research, Graduate Women in Science Eloise Gerry Fellowship, and the University of Utah Graduate Research Fellowship.

\section{Literature Cited}

Adams, R. P., T. A. Zanoni, E. V. Rudloff, and L. Hogge 1981. The south-western USA and northern Mexico oneseeded junipers: their volatile oils and evolution. Biochemical Systematics and Ecology 9:93-96.

Atsatt, S. R., and T. Ingram. 1983. Adaptation to oak and other fibrous, phenolic-rich foliage by a small mammal, Neotoma fuscipes. Oecologia 60:135-142.

Berenbaum, M. R., and A. R. Zangerl. 1994. Costs of inducible defense: protein limitation, growth, and detoxification in parsnip webworms. Ecology 75:2311-2317.

Boyle, R., and M. D. Dearing. 2003. Ingestion of juniper foliage reduces metabolic rates in woodrat (Neotoma) herbivores. Physiological and Biochemical Zoology 106:151158.

Boyle, R., S. McLean, W. J. Foley, and N. W. Davies. 1999a. Comparative metabolism of dietary terpene, $p$-cymene, in generalist and specialist folivorous marsupials. Journal of Chemical Ecology 25:2109-2127.

Boyle, R., S. McLean, W. J. Foley, B. D. Moore, N. W. Davies, and S. Branson. 1999b. Fate of the dietary terpene, p-cymene, in the male koala. Journal of Chemical Ecology 26:1095-1111.

Bozinovic, F., and F. F. Novoa. 1997. Metabolic costs of rodents feeding on plant chemical defenses: a comparison between an herbivore and an omnivore. Comparative Biochemistry and Physiology 117A:511-514.

Carpenter, F. L., and M. A. Hixon. 1988. A new function for torpor: fat conservation in a wild migrant hummingbird. Condor 90:373-378.

Dearing, M. D., A. M. Mangione, and W. H. Karasov. 2000. Diet breadth of mammalian herbivores: tests of the nutrient constraints and detoxification-limitations hypotheses. Oecologia 123:397-405.
Deerenberg, C., G. J. F. Overkamp, G. H. Visser, and S. Daan. 1998. Compensation in resting metabolism for experimentally increased activity. Journal of Comparative Physiology 168B:507-512.

Dell'Omo, G., M. G. Pleskacheva, D. P. Wolfer, H. P. Lipp, and R. F. Shore. 2003. Comparative effects of exposure to an organophosphate pesticide on locomotor activity of laboratory mice and five species of wild rodents. Bulletin of Environmental Contamination and Toxicology 70:138145.

Dial, K. P. 1988. Three sympatric species of Neotoma: dietary specialization and coexistence. Oecologia 76:531-537.

Dial, K. P., and C. J. Czaplewski. 1990. Do packrat middens accurately represent the animals' environment or diet? The Woodhouse Mesa study. Pages 43-58 in J. L. Bentacourt, T. R. Ven Devender, and P. S. Martin, editors. Fossil packrat middins: the last 40000 years of biotic change in the arid West. University of Arizona Press, Tucson, Arizona, USA. Foley, W. J. 1987. Digestion and energy metabolism in a small arboreal marsupial, the Greater Glider (Petauroides volans), fed high-terpene Eucalyptus foliage. Journal of Comparative Physiology 157:355-362.

Foley, W. J., G. R. Iason, and C. McArthur. 1999. Role of plant secondary metabolites in the nutritional ecology of mammalian herbivores: how far have we come in 25 years. Pages 131-209 in H. J. G. Jung and G. C. J. Faley, editors. Nutritional ecology of herbivores: Proceedings of the 5th International Symposium of the Nutrition of Herbivores. American Society of Animal Sciences, Savoy, Illinois, USA.

Foley, W. J., and C. McArthur. 1994. The effects and costs of allelochemicals for mammalian herbivores: an ecological perspective. Pages 370-391 in D. J. Chivers and P. Langer, editors. The digestive system in mammals: food, form and function. Cambridge University Press, Cambridge, UK.

Futuyma, D. J., and G. Moreno. 1988. The evolution of ecological specialization. Annual Review of Ecology and Systematics 19:207-233.

Garland, T. 1983. Scaling the ecological cost of transport to body mass in terrestrial mammals. American Naturalist 121:571-587.

Gordon, C. J. 1993. Temperature regulation in laboratory rodents. Press Syndicate of the University of Cambridge, Cambridge, UK.

Gordon, C. J., and B. K. Padnos. 2002. Dietary exposure to chlorpyrifos alters core temperature in the rat. Toxicology 177:215-226.

Guglielmo, C. G., and W. K. Karasov. 1996. Nutritional costs of plant secondary metabolite explain selective foraging by ruffed grouse. Ecology 77:1103-1115.

Handy, R. D., D. W. Sims, A. Giles, H. A. Campbell, and M. M. Musonda. 1999. Metabolic trade-off between locomotion and detoxification for maintenance of blood chemistry and growth parameters by rainbow trout (Oncorhynchus mykiss) during chronic dietary exposure copper. Aquatic Toxicology 47:23-41.

Hill, J. O., A. Latiff, and M. DiGirolamo. 1985. Effects of variable caloric restriction on utilization of ingested energy in rats. American Journal of Physiology 248:R549-R559.

Howe, R. J. 1978. Agonistic behavior of three sympatric species of woodrats (Neotoma mexicana, $N$. albigula, and N. stephensi. Journal of Mammalogy 59:780-786.

Iason, G. R., and A. H. Murray. 1996. The energy costs of ingestion of naturally occurring nontannin plant phenolics by sheep. Physiological Zoology 69:532-546.

Karasov, W. H. 1986. Energetics, physiology and vertebrate ecology. Trends in Ecology and Evolution 1:101-104.

Kenagy, G. J., S. M. Sharbaugh, and K. A. Nagy. 1989. Annual cycle of energy and time expenditure in a golden- 
mantled ground squirrel population. Oecologia 78:269282.

Klaassen, C. D. 2001. Cararett and Doull's toxicology: the basic science of poisons. McGraw Hill, New York, New York, USA.

Koteja, P., J. G. Swallow, P. A. Carter, and T. Garland. 1999. Energy cost of wheel running in house mice: implications for coadaptation of locomotion and energy budgets. Physiological and Biochemical Zoology 72:238-249.

Lamb, J. G., P. Marick, J. Sorensen, S. Haley, and M. D. Dearing. 2004. Liver biotransforming enzymes in Neotoma stephensi. Comparative Biochemistry and Physiology 138: 195-201.

Lambert, J. D., D. Zhao, R. O. Meyers, R. K. Kuester, B. N. Timmermann, and R. T. Dorr. 2002. Nordihydroguaiaretic acid: hepatotoxicity and detoxification in the mouse. Toxicon 40:1701-1708.

Lawler, I. R., W. J. Foley, B. M. Eschler, D. M. Pass, and K. Handasyde. 1998. Intraspecific variation in Eucalyptus secondary metabolites determines food intake by folivorous marsupials. Oecologia 116:160-169.

Mabry, T. J., and J. E. Gill. 1979. Sesquiterpene lactones and other terpenoids. Pages 501-537 in G. A. R. a. D. H. Janzen, editor. Herbivores: their interaction with secondary plant metabolites. Academic Press, New York, New York, USA.

Mackenzie, A. 1996. A trade-off for host plant utilization in the black bean aphid, Aphis fabae. Evolution 50:155-162.

Mangione, A. M., M. D. Dearing, and W. H. Karasov. 2000. Interpopulation differences in tolerance to creosote bush resin in desert woodrats (Neotoma lepida). Ecology 81: 2067-2076.

Mangione, A. M., M. D. Dearing, and W. H. Karasov. 2001. Detoxification in relation to toxin tolerance in desert woodrats eating creosote bush. Journal of Chemical Ecology 27: $2559-2578$.

Marsh, K. J., W. J. Foley, A. Cowling, and I. R. Wallis. 2003. Differential susceptibility to secondary compounds in $E u$ calyptus explains feeding by the common ringtail (Pseudocheirus peregrinus) and the common brushtail possum (Trichosurus vulpecula). Journal of Comparative Physiology 173B:69-76.

McDonald, K. A., and J. H. Brown. 1992. Using montane mammals to model extinctions due to global change. Conservation Biology 6:409-415.

McLean, J. A., and J. R. Speakman. 1999. Energy budgets of lactating and non-reproductive brown long-eared bats (Plecotus auritus) suggest females use compensation in lactation. Functional Ecology 13:360-372.

McLister, J. D., J. S. Sorensen, and M. D. Dearing. 2004. The effect of juniper (Juniperus monosperma) consumption on the cost of thermoregulation in the woodrats Neotoma albigula and Neotoma stephensi depends upon acclimation temperature. Physiological and Biochemical Zoology 77: 305-312.

McNab, B. K. 2002. The physiological ecology of vertebrates: a view from energetics. Cornell University Press, Ithaca, New York, USA.

Meyer, M. W., and W. H. Karasov. 1989. Antiherbivore chemistry of Larrea tridentata: effects on woodrat (Neotoma lepida) feeding and nutrition. Ecology 70:953-961.

Munch, I. C., N. H. Marckussen, and N. A. Oritsland. 1993. Resting oxygen consumption in rats during food restriction, starvation and refeeding. Acta Physiologica Scandinavica 148:335-340.

Pass, G. J., S. McLean, I. Stupans, and N. Davies. 2001. Microsomal metabolism of the terpene 1,8-cineole in the common brushtail possum (Trichosurus velpecula), koala (Phascolarctos cinereus), rat and human. Xenobiotica 31: 205-221.

Pass, G. J., S. McLean, I. Stupans, and N. Davies. 2002. Microsomal metabolism and enzyme kinetics of the terpene p-cymene in the common brushtail possum (Trichosurus velpecula), koala (Phascolarctos cinereus) and rat. Xenobiotica 32:383-397.

Randolph, P. A., J. C. Randolph, K. Mattingly, and M. M. Foster. 1977. Energy costs of reproduction in the cotton rat, Sigmodon hispidus. Ecology 58:31-45.

Rinaldi, R., E. Eliasson, S. Swedmark, and R. Morgenstern. 2002. Reactive intermediates and the dynamics of glutathione transferases. Drug Metabolism and Disposition 30: $1053-1058$.

SAS Institute. 2003. JMP statistics and graphics guide. Version 5.0.1.2. SAS Institute, Inc., Cary, North Carolina, USA.

Schmidt-Nielsen, K. 1997. Animal physiology: adaptations and environment. Fifth edition. Cambridge University Press, Cambridge, UK.

Silverstein, L., B. G. Swanson, and D. Moffett. 1996. Procyanidin from black beans (Phaseolus vulgaris) inhibits nutrient and electrolyte absorption in isolated rat ileum and induces secretion of chloride ion. Journal of Nutrition 126: $1688-1695$.

Sipes, I. G., and A. J. Gandolfi. 1986. Biotransformation of toxicants. Pages 64-98 in C. D. Klaasen, M. O. Amdur, and J. Doull, editors. Casarett and Doull's toxicology: the basic science of poisons. McMillan, New York, New York, USA.

Song, J., O. Kwon, S. Chen, R. Daruwala, P. Eck, J. B. Park, and M. Levine. 2002. Flavonoid inhibition of sodium-dependent vitamin $\mathrm{C}$ transporter 1 (SVCT1) and glucose transporter isoform 2 (GLUT2), intestinal transporters for vitamin $\mathrm{C}$ and glucose. The Journal of Biological Chemistry 277:15 252-15 260.

Song, Z. G., and D. H. Wang. 2002. The maximum metabolizable energy intake and the relationship with basal metabolic rate in the striped hamster Cricetulus barabensis. Acta Theriologica 47:417-423.

Sorensen, J. S., and M. D. Dearing. 2003. Elimination of plant toxins: an explanation for dietary specialization in mammalian herbivores. Oecologia 134:88-94.

Sorensen, J. S., J. D. McLister, and M. D. Dearing. 2005. Plant secondary metabolites compromise the energy budgets of specialist and generalist mammalian herbivores. Ecology 86:125-139.

Sorensen, J. S., C. A. Turnbull, and M. D. Dearing. 2004. A specialist herbivore (Neotoma stephensi) absorbs fewer plant toxins than a generalist (Neotoma albigula). Physiological and Biochemical Zoology 77:139-148.

Stapley, J., W. J. Foley, R. Cunningham, and B. Eschler. 2000. How well can common brushtail possums regulate their intake of Eucalyptus toxins? Journal of Comparative Physiology 170B:211-218.

Swingland, I. R., and P. J. Greenwood. 1983. The ecology of animal movement. Clarendon Press of Oxford University Press, Oxford, UK.

Taylor, C. R., K. Schmidt-Nielsen, and J. L. Raab. 1970. Scaling of energetic cost of running to body size in mammals. American Journal of Physiology 219:1104-1107.

Thomas, D. W., C. Samson, and J. Bergeron. 1988. Metabolic costs associated with the ingestion of plant phenolics by Microtus pennsylvanicus. Journal of Mammalogy 69:512515.

Vaughan, T. A., and C. J. Czaplewski. 1985. Reproduction in stephens woodrat, Neotoma stephensi, the wages of folivory. Journal of Mammalogy 66:429-443. 
Wade, G. N., and J. E. Schneider. 1992. Metabolic fuels and reproduction in female mammals. Neuroscience and Biobehavioral Reviews 16:235-272.

Weis, J. S., G. Smith, T. Zhoe, C. Santiago-Bass, and P. Weis. 2001. Effects of contaminants on behavior: biochemical mechanisms and ecological consequences. BioScience 51: 209-217.
Wiggins, N. L., C. McArthur, S. McLean, and R. Boyle. 2003. Effects of two plant secondary metabolites, cineole and gallic acid, on nightly feeding patterns of the common brushtail possum. Journal of Chemical Ecology 29:14471464.

Zar, J. H. 1984. Biostatistical analysis. Second edition. Prentice Hall, Englewood Cliffs, New Jersey, USA.

\section{APPENDIX}

A table showing nutrient composition of control and creosote diets is presented in ESA's Electronic Data Archive: Ecological Archives E086-009-A1. 